\title{
Twenty years after index reaction: Recall phenomenon with anaphylactic reaction upon intradermal test with low molecular weight heparins
}

\author{
Julia Pickert · Stefan Mühlenbein · Wolfgang Pfützner
}

Received: 7 January 2021 / Accepted: 8 April 2021 / Published online: 19 July 2021

(C) The Author(s) 2021

Keywords Skin test - Recall urticaria - Anaphylaxis · Immediate-type hypersensitivity $\cdot$ Allergy

\section{Background}

Heparins are mucopolysaccharides with a strong protein-binding potency mainly used as prophylactic treatment for the prevention of thrombosis. Allergic reactions to heparins are common but generally present as delayed-type hypersensitivity reactions with localized infiltrated plaques occurring hours to days after their application at the injection site. Immediate-type hypersensitivity is very rare, even though these drug compounds are commonly administered.

Investigation for immediate-type hypersensitivity to heparins includes detailed patient history, skin testing and-if indicated-provocation tests. Several cross-reactions of unfractionated to low-molecularweight heparins or heparinoids have been described [1]. In some patients with cross-reactivity between various heparins and semisynthetic heparinoids, even combined allergy to heparins and recombinant hirudins, which otherwise serve as safe alternatives in these individuals, has been reported [1]. Since heparins are histamine-liberating drugs, false positive skin tests results might occur.

We describe a patient with recall urticaria (RU) at previous low molecular weight heparin (LMWH) injection sites elicited almost 20 years later by intradermal skin testing at the forearms with several LMWHs and heparin. This unusual reaction pattern points to

\footnotetext{
J. Pickert · S. Mühlenbein · Prof. Dr. W. Pfützner ( $₫)$ Department of Dermatology and Allergology, Allergy Center Hessen, University Medical Center Marburg, Baldingerstraße, 35033 Marburg, Germany wolfgang.pfuetzner@med.uni-marburg.de
}

a so far unexplained mechanism of long-lasting 'tissue type I memory'.

\section{Case representation}

A 52-year-old man reported experiencing anaphylaxis in 1998 after subcutaneous LMWH injection for thrombosis prophylaxis. About $15 \mathrm{~min}$ after injection, generalized urticaria, dyspnea and circulatory collapse occurred. Symptoms responded rapidly to treatment with anti-allergic drugs of unknown origin. Subsequently, anticoagulation was switched to the heparinoid danaparoid-Na (Orgaran $\left.{ }^{\circledR}\right)$, which was well tolerated. He had never received LWMHs since then.

Almost 20 years later, we performed skin tests on both forearms with different LMWHs including certoparin-Na, nadroparin-Ca, enoxaparin-Na, dalteparin- $\mathrm{Na}$ as well as heparin-Na and heparin-Ca, fondaparinux-Na and danaparoid-Na. Skin prick tests showed wheals of $3 \mathrm{~mm}$ diameter for certoparin-Na and fondaparinux- $\mathrm{Na}$, considered negative results according to drug skin testing guidelines. We thus continued by performing intradermal tests with the above mentioned substances, diluted according to drug testing guidelines. About $10 \mathrm{~min}$ later, the patient was in cold sweat, showing acute dyspnea and multiple urticarial wheals on the lower abdominal wall (Fig. 1). Symptoms improved rapidly upon treatment with intravenous dimetidene maleate, prednisolone and an inhalative $\beta$-2-sympathomimetic.

Notably, intradermal test sites showed positive results for LMWHs (certoparin-Na: $10 \mathrm{~mm}$ wheal, enoxaparin-Na: $7 \mathrm{~mm}$ wheal,) heparin (heparin-Na: $7 \mathrm{~mm}$ wheal) and fondaparinux (fondaparinux- Na $6 \mathrm{~mm}$ wheal) but not for danaparoid-Na. Thus, according to the history and skin test results, diagnosis of immediate type allergy to heparin appearing by 


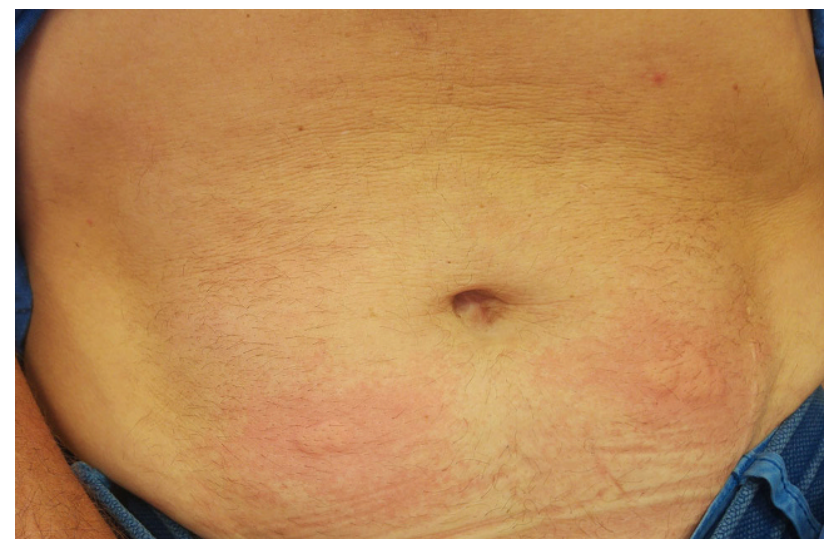

Fig. 1 Recall urticaria: wheals appearing on the lower abdominal wall (at former injection sites) about $10 \mathrm{~min}$ after intradermal testing of low molecular weight histamines on the forearm (ODepartment of Dermatology and Allergology, University of Marburg)

both anaphylaxis and RU was established, together with cross-sensitization to the structurally related compound fondaparinux. Remarkably, these reactions were elicited solely by intradermal testing.

\section{Conclusion}

Recall urticaria (RU) was described for the first time in patients undergoing subcutaneous immunotherapy [2]. Only two cases of (potential) RU to low molecular weight heparin (LMWH) have been reported so far. First, a pregnant woman experienced localized urticarial plaques shortly after every LMWH injection 6 weeks following treatment initiation [3]. Notably, she developed pruritus on the contralateral arm one hour after positive intradermal testing; however, no lesions were visible at the former injection sites. Second, a woman treated with dalteparin presented wheals one year after previous administration of the drug at current as well as former injection sites [4]. While prick as well as intradermal tests with both unfractionated and low molecular weight heparins turned out negative, she developed urticae at the lower quadrants of her abdomen, where dalteparin had been previously injected.

There have been other descriptions of RU, triggered for example by antibiotics or tumor peptide vaccination. However, to our knowledge, RU and simultaneous anaphylaxis caused by skin testing with $\mathrm{LMWH}$, especially such a long period of time after the index reaction, has not been reported so far.

Anaphylaxis induced by skin tests is extremely rare, but may occur. Potential elicitors are mainly fresh food (applied by prick-to-prick testing), hymenoptera venom and $\beta$-lactam antibiotics, while aeroallergens are unlikely triggers. All in all, the likelyhood is much lower for skin prick than for intradermal testing with history of previous anaphylaxis, early childhood, pregnancy, uncontrolled asthma, and high degree

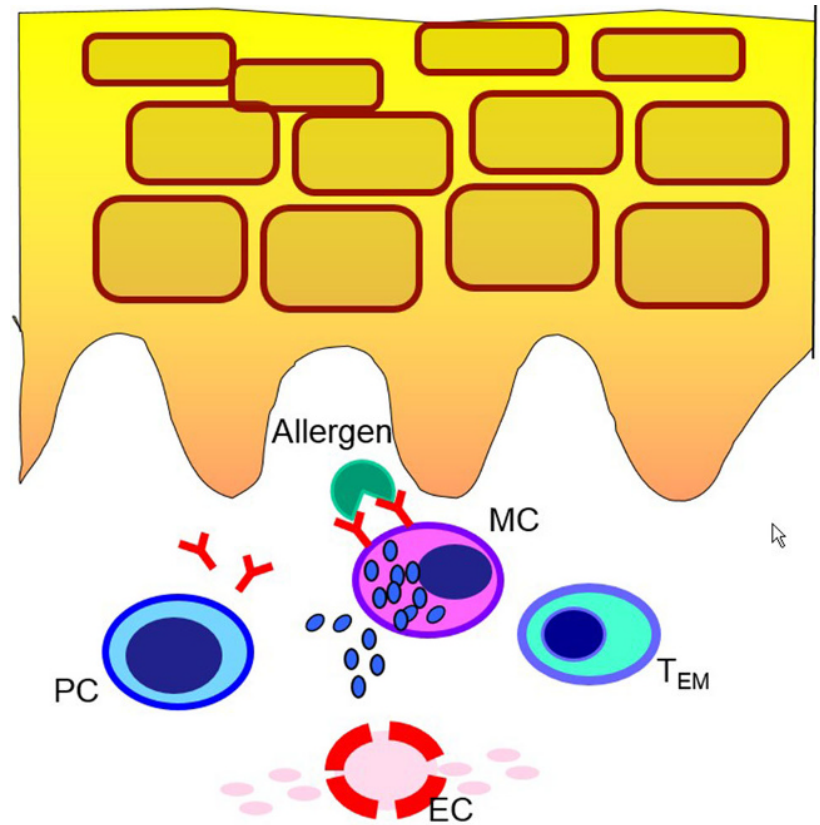

Fig. 2 Recall urticaria is dependent on 'immunologic tissue memory' which may rest on long-term allergen-specific mast cell (MC) reagibility, long-living IgE-producing plasma cells $(\mathrm{PC})$, resident T-effector memory cells ( $\mathrm{T}_{\mathrm{EM}}$ ) or increased tissue effector cell reactivity, for example of endothelial cells (EC), in the skin

of hypersensitivity considered potential risk factors [5]. Nevertheless, even though anaphylaxis upon skin testing is very unusual, our case illustrates the need to be prepared for potential emergency treatment.

While RU is well characterized clinically, its underlying pathogenesis is poorly understood. As RU can still be induced a very long time after the initial allergen exposure (in our patient about 20 years later), one has to consider long-lasting immunologic memory mechanisms being responsible for this type of hypersensitivity reaction. As mast cells are crucial for the elicitation of immediate-type allergy including acute urticaria, they are one possible candidate for mediating localized 'immunologic tissue memory'. Increased mast cell frequency or reactivity at the site of reaction has been proposed; however, a skin biopsy taken from RU failed to show enhanced mast cells numbers compared to healthy controls [4]. Other contributors might be long-living IgE-producing plasma cells replenishing the allergen-specific IgE antibodies on the surface of the mast cells, resident memory effector T-cells providing a permissive environment for the preserved local reactivity or an increased responsiveness of effector cells targeted by mediators released from mast cells (Fig. 2; [6]).

In summary, our case of anaphylaxis associated with $\mathrm{RU}$ upon skin testing with heparins 20 years after the index reaction and without any further contact to the culprit drug may provide a new point of view on the clinical aspects and significance of recall phenomena and long-lasting 'tissue type I memory'. 
Nevertheless, RU must not always necessarily reflect a still existing systemic allergic predisposition, as we recently observed RU at the upper arm of a wasp venom allergic patient (who had been treated by allergen immunotherapy with venom injections in both upper arms), when tolerating a controlled wasp sting challenge at the other upper arm, confirming successful desensitization by venom immunotherapy.

Funding Open Access funding enabled and organized by Projekt DEAL.

Conflict of interest J. Pickert, S. Mühlenbein and W. Pfützner declare that they have no competing interests.

Open Access This article is licensed under a Creative Commons Attribution 4.0 International License, which permits use, sharing, adaptation, distribution and reproduction in any medium or format, as long as you give appropriate credit to the original author(s) and the source, provide a link to the Creative Commons licence, and indicate if changes were made. The images or other third party material in this article are included in the article's Creative Commons licence, unless indicated otherwise in a credit line to the material. If material is not included in the article's Creative Commons licence and your intended use is not permitted by statutory regulation or exceeds the permitted use, you will need to obtain permission directly from the copyright holder. To view a copy of this licence, visit http://creativecommons.org/licenses/by/4.0/.

\section{References}

1. Jappe U. Allergy to heparins and anticoagulants with a similar pharmacological profile: an update. Blood Coagul Fibrinolysis. 2006;17:605-13.

2. Kelso JM, Hugh MY, Lin FL. Recall urticaria. J Allergy Clin Immunol. 1994;93:949-50.

3. Caliskaner Z, Karaayvaz M, Oztürk S. Recurrent urticaria lesions in a heparin-allergic patient: most likely another form of 'recall urticaria. J Investig Allergol Clin Immunol. 2005;15:78-80.

4. Weber HO, Fischer J, Kneilling M, Caroli U, Rocken M, Biedermann T. Recall urticaria induced by skin tests with heparin. BrJ Dermatol. 2009;161:187-9.

5. Liccardi G, D'Amato G, Walter Canonica G, Salzillo A, Piccolo A, Passalacqua G. Systemic reactions from skin testing: literature review. J Investig Allergol Clin Immunol. 2006; $16: 75-8$.

6. Luger EO, Wegmann M, Achatz G, Worm M, Renz H, Radbruch A. Allergy for a lifetime? Allergol Int. 2010;59:1-8. 